\title{
Avaliação dos indicadores do aterro controlado do Município de Alagoa Grande-PB e seus impactos ambientais*
}

\section{Rennêr Ribeiro Pinto, Ana Caroline Silva Braz, Pablyano Rodrigues dos Santos, Grace Kelly Neves da Silva, Gerlane Henrique da Silva, Fábio de Melo Resende*}

Curso de Tecnologia em Produção Sucroalcooleira. Centro de Tecnologia e Desenvolvimento Regional - CTDR/UFPB (Campus V). Avenida dos Escoteiros, s/n $\mathrm{n}^{\mathrm{o}}$. Mangabeira VII - Distrito Industrial de Mangabeira, João Pessoa-PB (CEP 58055-000). *E-mail: fabiomresende@ig.com.br.

Resumo. Devido ao aumento populacional assim como o aumento da demanda de consumo, a geração de resíduos sólidos vem se tornado um sério problema nos dias atuais. A disposição inadequada desses resíduos sólidos no ambiente causa inúmeros impactos ambientais, para isso é necessário que haja o seu tratamento, onde então se faz necessário estar à disposição um aterro sanitário. Segundo dados da última Pesquisa Nacional de Saneamento Básico, o percentual de municípios que destinavam seus resíduos a vazadouros a céu aberto (lixão) caiu de $72,3 \%$ para $50,8 \%$, enquanto os que utilizam aterros sanitários subiram para 27,7\%. Este trabalho teve como objetivo avaliar a situação e os impactos ambientais oriundos do aterro controlado do Município de Alagoa Grande-PB. Em visita in loco ao município aplicou-se o formulário IQAR/CETESB, para diagnosticar as principais características do local, a infraestrutura implantada e as condições de operação. O preenchimento das variáveis do formulário permitiu alcançar um IQAR de 5,1, enquadrando o aterro controlado em condições inadequadas para destinação final de resíduos sólidos.

Palavras-chave: Resíduos sólidos; Lixão; Alagoa Grande.

Abstract. Evaluation of the indicators of the landfill controlled the Municipallity of Alagoa Grande-PB and their environmental impacts. Due to the increase in population as well as the increase in consumer demand, the generation of solid waste has become a serious problem in the present day. At the disposal of these solid waste on the environment inadequate cause numerous environmental impacts, it is necessary that there is treatment, where if necessary a sanitary landfill. According to the last National Survey of Basic Sanitation indicate that the percentage of municipalities that were its waste dumps (dump) the open fell $72.3 \%$ to $50.8 \%$, while those using landfills rose to $27.7 \%$. This work aimed to evaluate the situation and environmental impacts from landfill controlled the Municipality of Alagoa Grande, State of Paraíba, Brazil. On a visit in loco to the municipality applied the form IQAR/CETESB, to diagnose the main features of the place, the infrastructure deployed and operating conditions. The filling of the variables of the form allowed us to
Recebido:

17/11/2015

Aceito:

25/01/2016

Publicado:

30/06/2016

Acesso Aberto

Artigo completo

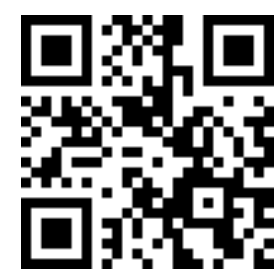

ORCIID

() 0000-0002-5003-9486 Rennêr Ribeiro Pinto (C) 0000-0002-5022-6214 Ana Caroline Silva Braz

(c) 0000-0002-3988-3555

Pablyano Rodrigues dos Santos

(c) 0000-0003-0449-6309

Grace Kelly Neves da Silva

(-) 0000-0002-3277-8031

Gerlane Henrique da Silva

\footnotetext{
*Apresentado no Congresso Brasileiro de Gestão Ambiental e Sustentabilidade - Congestas 2015, João Pessoa-PB, 9 a 11 de dezembro de 2015.
} 
achieve an IQAR of 5.1, framing the controlled landfill in $0000-0001-6552-6124$ inappropriate conditions for final disposal of solid waste.

Fábio de Melo Resende

Keywords: Solid waste; Garbage dump; Alagoa Grande.

\section{Introdução}

Os resíduos sólidos urbanos gerados nas cidades brasileiras e em localidades de diferentes países, ainda são um problema. Em países ricos que geram maiores quantidades de resíduos, existe mais capacidade de equacionamento da gestão, por um somatório de fatores que incluem recursos econômicos, preocupação ambiental da população e desenvolvimento tecnológico (Jacobi e Bessen, 2011).

A gestão e a disposição inadequada dos resíduos sólidos causam impactos socioambientais, tais como degradação do solo, comprometimento dos corpos d'água e mananciais, intensificação de enchentes, contribuição para a poluição do ar e proliferação de vetores de importância sanitária nos centros urbanos e catação em condições insalubres nas ruas e nas áreas de disposição final (Besen et al., 2010). A gestão integrada e sustentável dos resíduos sólidos inclui a redução da produção nas fontes geradoras, $\mathrm{o}$ reaproveitamento, a coleta seletiva com inclusão de catadores de materiais recicláveis e a reciclagem, e ainda a recuperação de energia (Adedipe et al., 2005).

Apesar dos avanços ocorridos na legislação brasileira sobre resíduos sólidos, proporcionados pela Lei $\mathrm{n}^{\mathrm{o}} 12.305$, de 2 de agosto de 2010, que instituiu a Política Nacional de Resíduos Sólidos, ainda é comum a existência de cidades de pequeno e médio porte que possuem lixões e aterros controlados como único local de descarte de seus resíduos sólidos urbanos (Brasil, 2010).

Lixão é uma forma inadequada de disposição final de resíduos sólidos, que se caracteriza pela simples descarga do lixo sobre o solo, sem medidas de proteção ao meio ambiente ou à saúde pública, isto é, descarga de resíduos a céu aberto (Reis, 2001). Com o objetivo de amenizar os depósitos a céu aberto, foram criados os sanitário. Normalmente, ele é uma célula próxima ao lixão, que foi remediada, ou seja, que recebeu cobertura de grama e argila. Nesta situação, há uma contenção do lixo que, depois de lançado no depósito, é coberto por uma camada de terra. Este sistema minimiza o mau cheiro e o impacto visual, além de evitar a proliferação de insetos e animais. Porém, não há impermeabilização de base (o que evitaria que o material contamine o solo e o lençol d'água), nem sistema de tratamento do chorume ou do biogás (Instituto Brookfield, 2012). Segundo Reis (2001), aterro sanitário é o método que utiliza princípios de engenharia para confinar resíduos sólidos à menor área possível e reduzi-los ao menor volume possível, cobrindo-os com uma camada de terra na conclusão da jornada de trabalho ou a intervalos menores.

Estudos que avaliam a forma de gestão das áreas de disposição dos resíduos sólidos consistem em uma demanda atual e de expressiva importância para o estabelecimento de medidas controle dessas áreas. Para a avaliação da qualidade da disposição final de resíduos, a Companhia Ambiental do Estado de São Paulo (CETESB) criou o Índice de Qualidade de Aterro de Resíduos (IQAR). Esse método passou por transformações ao longo dos anos. De acordo com a CETESB (2011), que avalia as características locacionais, estruturais e operacionais dos locais de tratamento e disposição de resíduos (Ferreira et al., 2014).

Tendo como foco principal nesse trabalho o tema acima discutido, optou-se pelo município de Alagoa Grande-PB para trabalhar. Sua população está em torno de 28.479 habitantes, tendo uma área igual a $320.558 \mathrm{~km}^{2}$ (IBGE, 2010). O Índice de Qualidade de Aterro de Resíduos (IQAR) foi a ferramenta utilizada no diagnóstico da gestão da área de disposição final dos resíduos sólidos urbanos do Município de aterros controlados, uma categoria 
intermediária entre o lixão e 0 aterro Alagoa Grande-PB, sendo este o objetivo principal do presente trabalho.

\section{Material e métodos}

$\mathrm{O}$ aterro localiza-se a cerca de $3 \mathrm{~km}$ do centro do município (Figura 1). As informações para o cálculo do IQR foram coletadas por meio de visita in loco ao Aterro Controlado do Município de Alagoa Grande-PB no mês de agosto de 2015, utilizando-se da metodologia adotada pela CETESB, Índice de Qualidade de Aterro de Resíduos (IQAR), que consiste na aplicação do questionário padronizado desenvolvido check list, considerando:

a) Características do local: compreendem; a capacidade de suporte do solo, proximidades dos núcleos habitacionais, proximidades dos corpos de águas, profundidade do lençol freático, permeabilidade do solo, disponibilidade do material para recobrimento, qualidade do material para recobrimento, condições dos sistemas viários trânsitos e acessos, isolamento visual da vizinhança e a legalidade da localização.

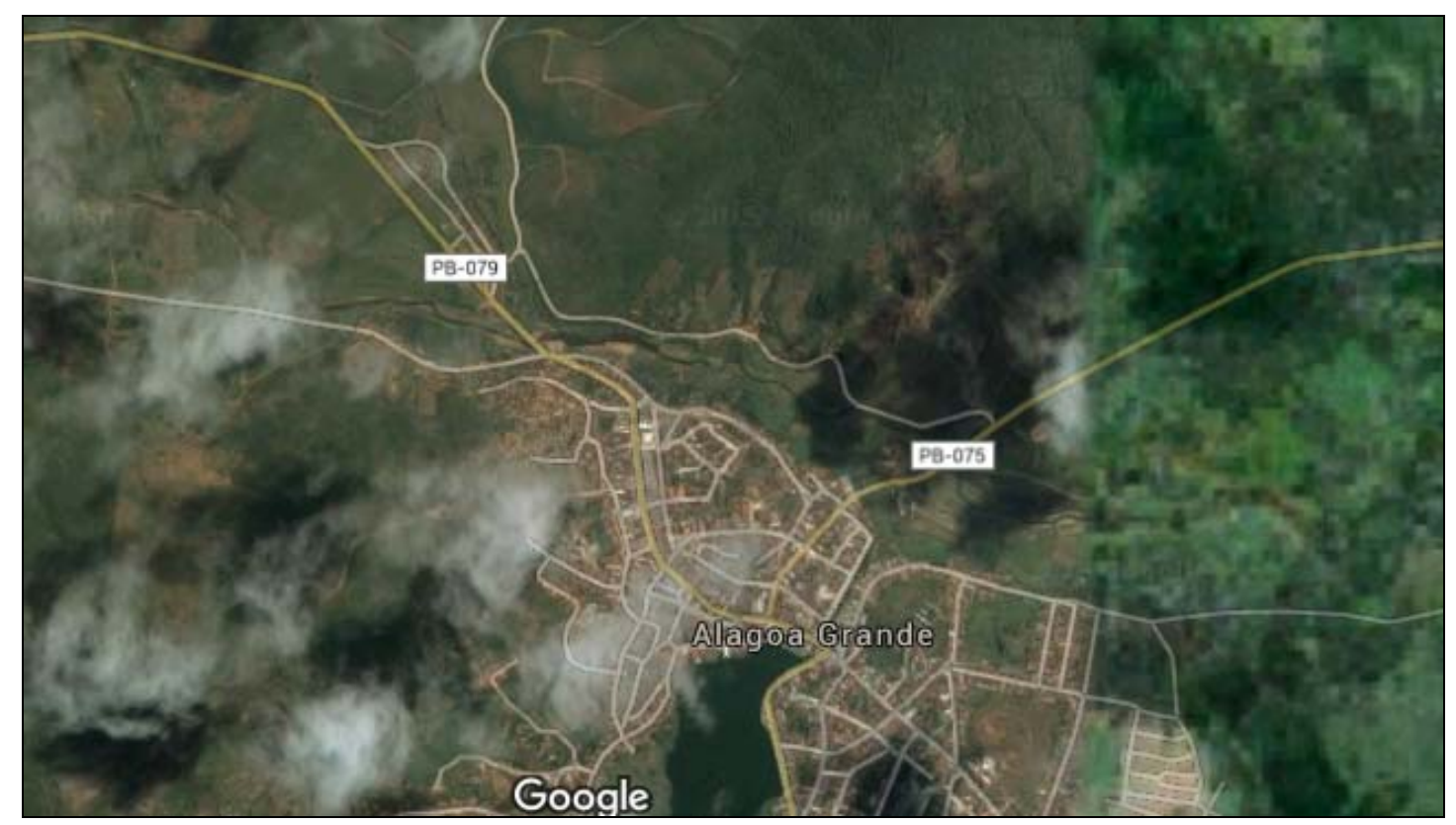

Figura 1. Localização do aterro controlado do Municipio de Alagoa Grande-PB. Fonte: Google Maps.

b) Infraestrutura implantada: compreendem os itens relacionados: o cercamento da área, portaria e guarita, impermeabilização da base do aterro, drenagem de chorume, drenagem de águas pluviais definitivas, drenagem de águas pluviais provisórias, trator de esteira ou compatível, outros equipamentos, sistema de tratamento de chorume, acesso à frente de trabalho, vigilantes, sistema de drenagem de gases, controle de recebimento de cargas, monitoramento de água subterrânea, atendimento a estipulação de projeto. c) Condições

operacionais:

correspondem as avaliações quanto: aspecto geral, ocorrência de lixo a descoberto, recobrimento de lixo, presenças de urubus ou gaivotas, presenças de moscas, presenças de catadores, criações de animais (porcos, bois), descargas de resíduos de saúde, funcionamento da drenagem pluvial definitiva, funcionamento da drenagem pluvial provisória, descargas de resíduos industriais, funcionamento da drenagem de chorume, funcionamento do sistema de tratamento, funcionamento do sistema de monitoramento da água subterrânea, manutenções dos acessos internos. 
Todos esses fatores possuem pesos diferentes. As pontuações apresentam como base matemática, a soma do subtotal de cada item, o total, dividido por 13, determina o valor do IQR.

Sendo possível assim, de acordo com a avaliação dos valores referentes aos pesos atribuídos às variáveis citadas anteriormente de cada macro conjunto $(\mathrm{a}, \mathrm{b}$, c), enquadrar as instalações de destinação dos resíduos sólidos urbanos em três condições: inadequadas, controladas ou adequadas (Tabela 1).

Tabela 1. Enquadramento das instalações de tratamento e/ou destinação final de resíduos sólidos em função do IQAR.

\begin{tabular}{|l|c|}
\hline IQAR & Avaliação \\
\hline $0,00 \leq \mathrm{IQAR} \geq 6,00$ & Condições Inadequadas \\
\hline $6,01 \leq \mathrm{IQAR} \geq 8,00$ & Condições Controladas \\
\hline $8,01 \leq \mathrm{IQAR} \geq 10,00$ & Condições Adequadas \\
\hline
\end{tabular}

Fonte: Consoni et al. (2000).

\section{Resultado e discussão}

$\mathrm{Na}$ visita in loco ao município, constatou-se que a realidade está muito distante do que se apregoa a legislação na Lei $\mathrm{n}^{-}$12.305/2010 (Brasil, 2010), sendo possível observar que sua gerência mesmo não dispondo dos sistemas de impermeabilização, captação de chorume e de gases gerados pela decomposição do lixo, utiliza-se de alguns princípios de engenharia para confinar os resíduos sólidos, cobrindo-os com material inerte na conclusão de cada jornada de trabalho.

Diante dessas informações, pode-se afirmar que o Município de Alagoa Grande$\mathrm{PB}$, diferentemente das informações preliminares coletadas, detém de um aterro controlado de pequeno porte, para disposição final de seus resíduos sólidos, objetivando a minimização dos riscos à saúde pública e a sua segurança (Figura 2).

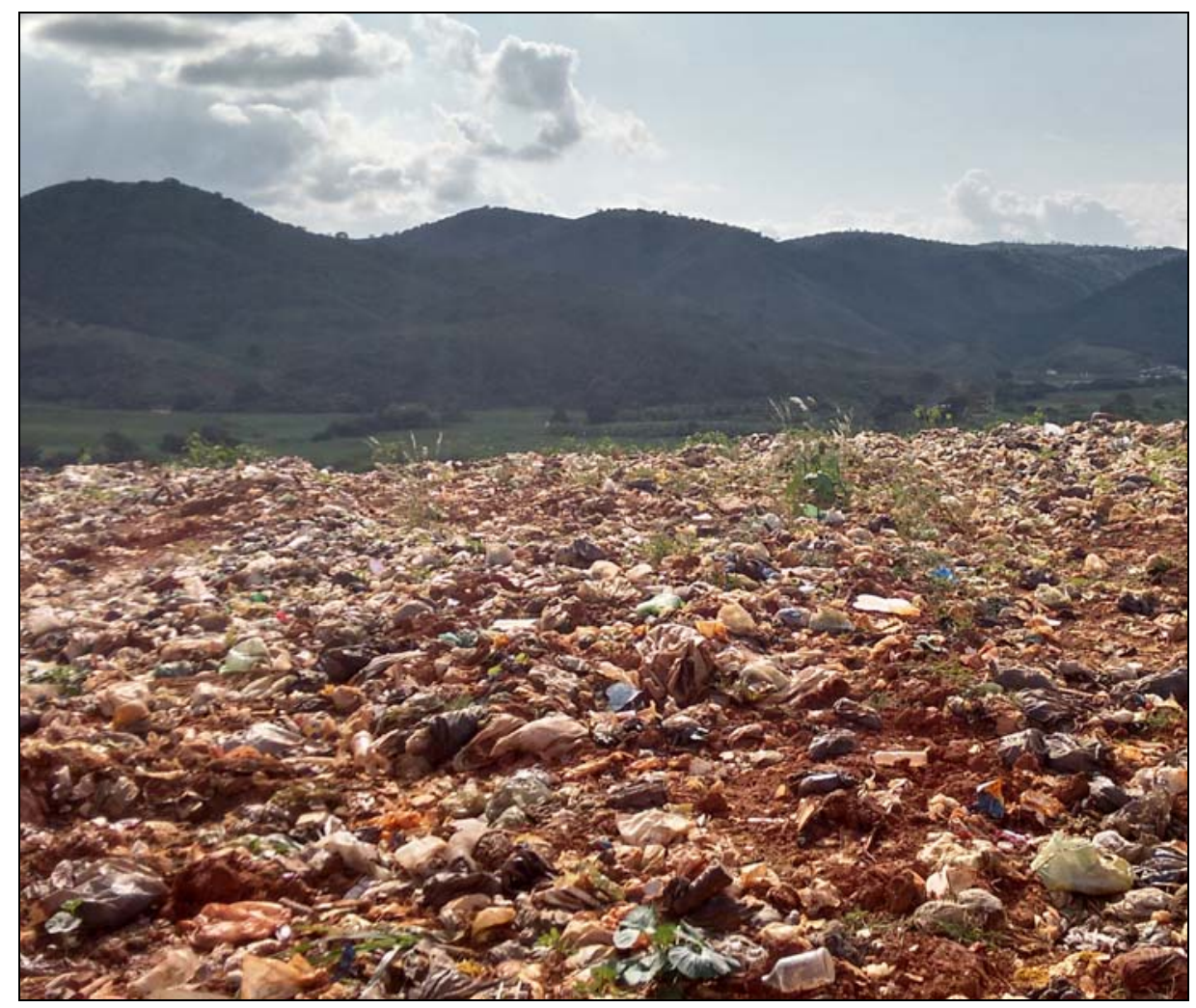

Figura 2. Disposição final dos resíduos sólidos do Município de Alagoa Grande-PB. 
De responsabilidade da Prefeitura Municipal de Alagoa Grande, a área de disposição de resíduos do município não possui licença ambiental de funcionamento, mesmo assim opera recebendo apenas resíduo doméstico e resíduo de restos de animais (oriundos do abatedouro municipal). As práticas de destinação dos resíduos de origem animal, geralmente, utilizadas, são: aterros, enterramento, compostagem, queima, incineração e reciclagem. Os aterros representam uma péssima escolha por não apresentar temperaturas adequadas para eliminar bactérias e esporos resistentes ao calor.

A seleção da área de implantação para a disposição do resíduo é uma escolha determinante do ponto de vista técnico e ambiental, pois esse fator está diretamente ligado ao seu funcionamento e operação. A região onde está situado o aterro controlado é de difíceis condições, pois se encontra em local íngreme, sob as coordenadas geográficas $\quad 7^{\circ} 00^{\prime} 59,5^{\prime} \mathrm{S}$ e $35^{\circ} 37^{\prime} 52,1 " \mathrm{~W}$, e de difícil acesso (Figuras 3 e 4 ).

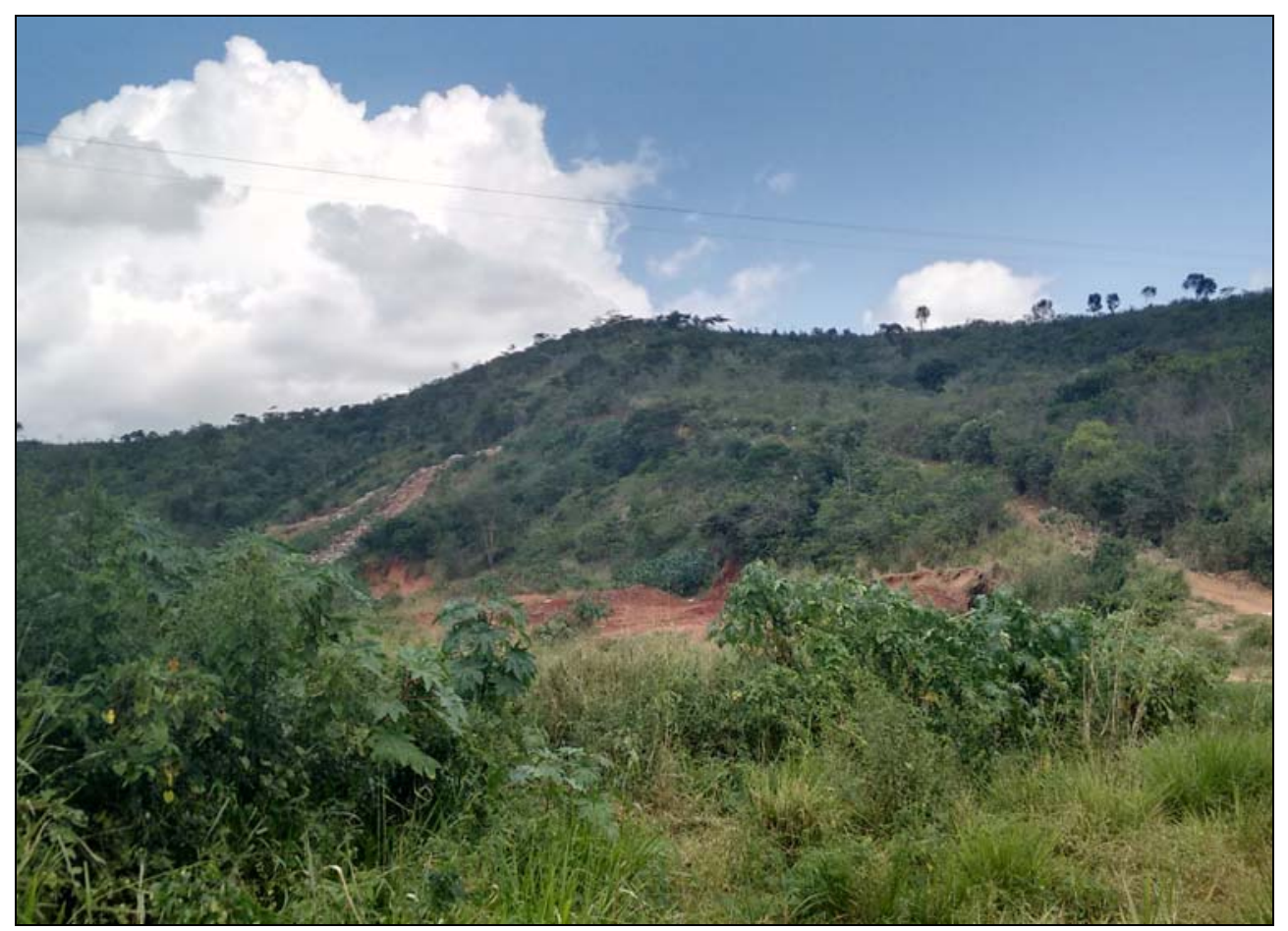

Figura 3. Visão parcial do Aterro Controlado do Município de Alagoa Grande-PB.

Os aterros são diferenciados basicamente pelas formas construtivas e operacionais adotadas, isto ocorre devido ao tipo de terreno. Dentre as principais formas adotas, podem ser divididas em três formas de aterramentos: trincheira, rampa e área.

Como discutido anteriormente sobre a declividade da área, neste ponto ela se apresenta favorável para a forma de aterramento pelo método de rampa. Tal informação comprova que o método de rampa adotado pela gerência municipal é a correta para tal situação do aterro. Para formar as células de aterramento, o método de rampa consiste com o aproveitamento de um talude, natural ou construído, aonde os resíduos vão sendo depositados e compactados, seguindo a declividade existente, com o recobrimento necessário no final de cada etapa de trabalho prosseguindo até que as células em construção atinjam o topo do declive da parte superior e lateral onde o lixo é compactado de encontro a esse talude. O material de cobertura é retirado por escavação antecipada na própria frente de trabalho (Figura 5). 


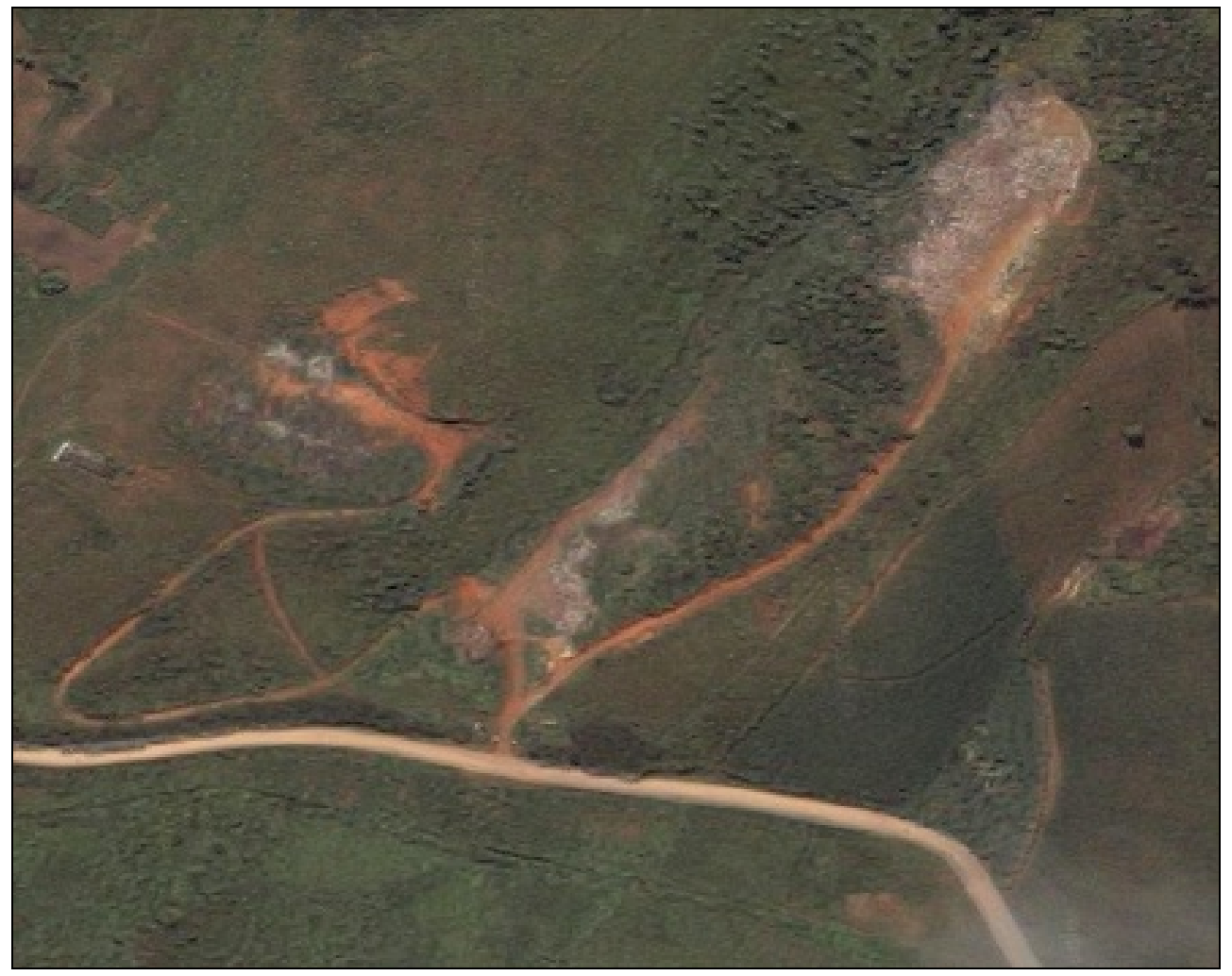

Figura 4. Visão aérea do Aterro Controlado do Município de Alagoa Grande-PB.

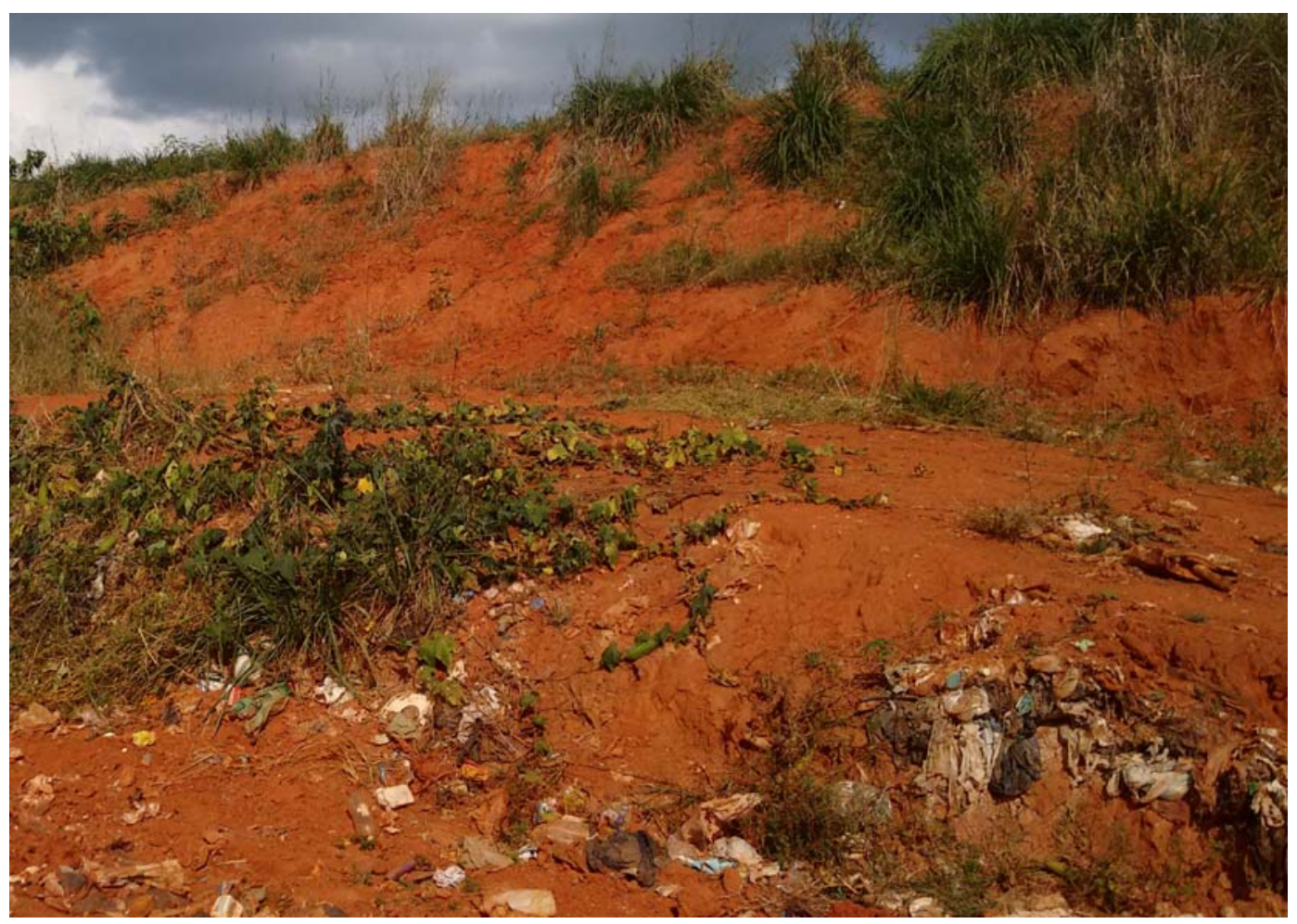

Figura 5. Método de rampa em execução.

Rev. Bras. Gest. Amb. Sustent., 2016, v. 3, n. 4, p.69-77. 
Entretanto, um dos grandes problemas encontrados no gerenciamento do aterro estudado, diz respeito à produção e ao tratamento inexistente do chorume produzido. O chorume é formado pela solubilização de componentes do lixo na água, principalmente da chuva. Essa água fica em contato com o lixo durante certo período e, por ação natural da gravidade, percola através da porosidade existente até encontrar uma camada impermeável do solo, formada por rochas, ou mesmo superfícies previamente preparadas para receber o lixo, onde acumula e escoa.

Chorumes de aterros geralmente contêm altas concentrações de compostos orgânicos, e frequentemente também contêm altas concentrações de metais pesados e sais inorgânicos. Nos aterros sanitários, onde ocorre à disposição planejada dos resíduos sólidos, normalmente o chorume é canalizado para um tanque, podendo haver ou não um prétratamento. $\mathrm{O}$ chorume gerado pelo aterro controlado estudado está sendo despejado diretamente no solo sem nenhum tipo de manejo.

A percolação do chorume está emanando mau cheiro, infiltrando-se no solo, atraindo animais (insetos e roedores, responsáveis pela transmissão de doenças graves) e pode está elevando o risco de contaminação de lençóis freáticos e de leitos de rios naquela região.Diante dos pontos apresentados, o aterro está infligindo mais uma legislação sendo esta a NBR 13896/1997, da Associação Brasileira de Normas Técnicas (ABNT, 1997), que dispõe sobre as condições mínimas estabelecidas para a construção de um aterro sanitário.

A NBR 13896/1997 exige que no projeto de um aterro inclua-se um sistema de coleta, drenagem e tratamento de líquidos percolados. A ineficiência encontrada no local se deve ao não comprometimento de gerências anteriores, culminando na deterioração de toda a tubulação que faria o transporte do chorume à estação de tratamento (Figura 6).

A existência de um corpo d' água a menos de $200 \mathrm{~m}$ do aterro controlado juntamente com núcleo habitacionais presentes no local (Figura 7), foram outros problemas encontrados que infligem a NBR 13896/1997. De acordo com a NBR, o aterro deve está localizado a uma distância mínima de $200 \mathrm{~m}$ de qualquer curso d' água, e que esteja a uma distância superior a $500 \mathrm{~m}$ de núcleos habitacionais, dessa forma agravando a situação no local.

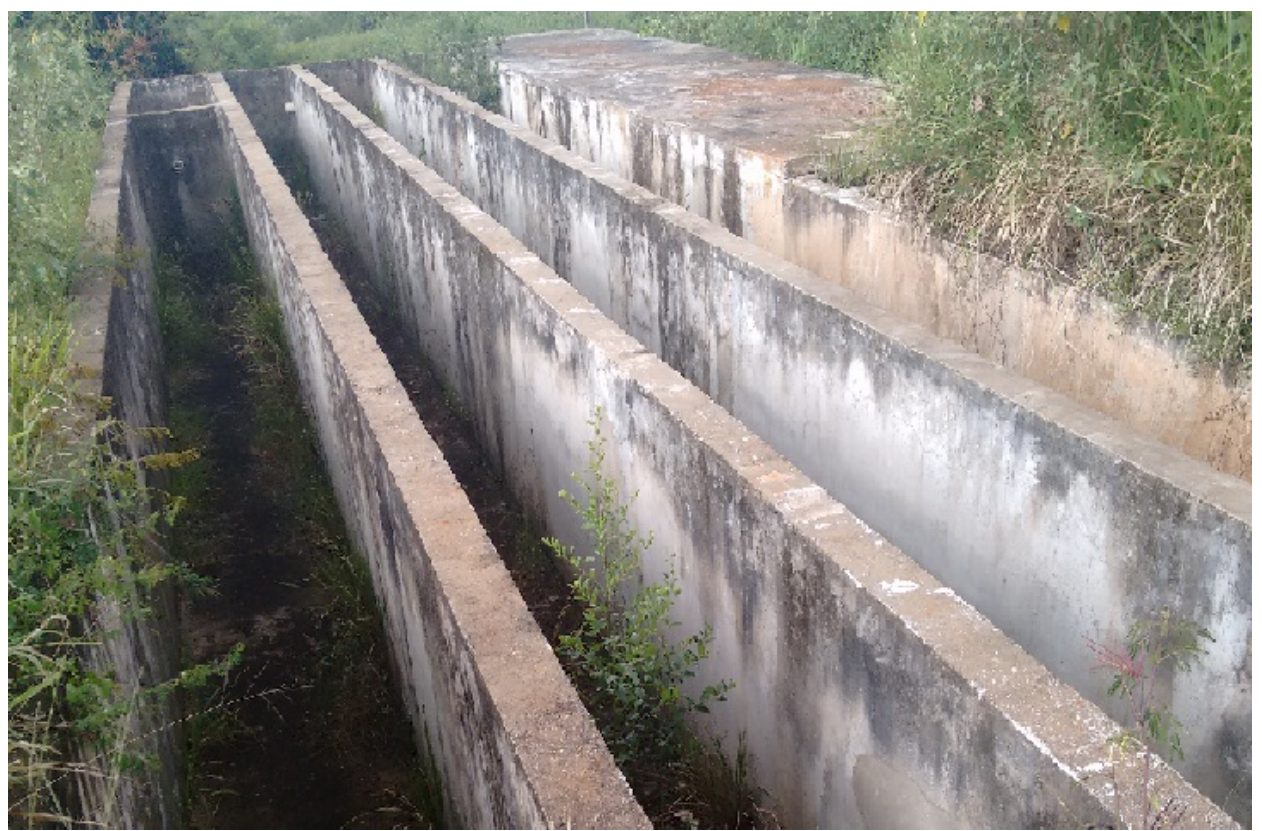

Figura 6. Deterioração da estação de tratamento do chorume. 


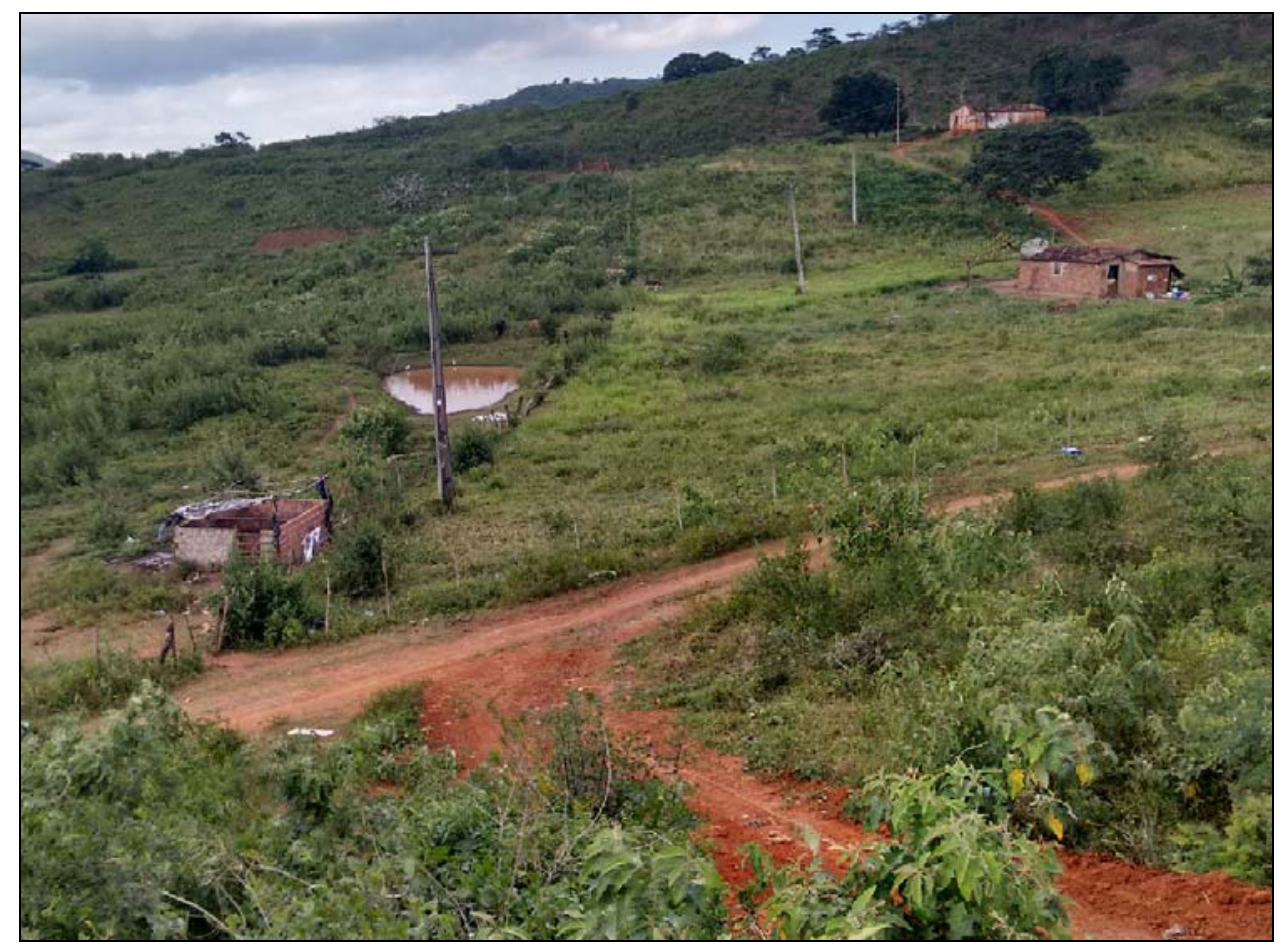

Figura 7. Núcleo habitacional e corpo de água presentes ao redor do aterro.

Outro grande problema detectado foi rachaduras no solo, provenientes não só da disposição do chorume, mas também da geração de biogás proveniente da estabilização dos materiais orgânicos biologicamente decomponíveis presentes nos resíduos sólidos. Infligindo novamente a NBR 13896/1997 que considera desejável o local do aterro que possua uma permeabilidade de $10^{-6} \mathrm{~cm} / \mathrm{s}$ e uma zona saturada com espessura superior a 3,0 m.

Assim como o chorume, a geração de biogás emana mau cheiro, devido à presença do gás sulfídrico, além de provocar prejuízos ambientais acarretados pela presença de metano e dióxido de carbono, responsáveis pelo efeito estufa, descumprindo assim as recomendações da ABNT-NBR 13896/1997, que determina que todo aterro deve ser projetado de maneira a minimizar as emissões gasosas e promover a captação e tratamento adequado das eventuais emanações. Assim, o aterro deve ser operado e mantido de forma a minimizar a possibilidade de fogo, explosão ou derramamento/vazamento de resíduos que possam constituir ameaça a saúde humana ou ao meio ambiente.
A partir das informações adquiridas na visita in loco, foi aplicado o formulário de Índice de Qualidade de Aterro de Resíduos (IQAR), preenchendo os quesitos presente no formulário, sendo estas divididas nos três macroconjuntos citados no início do estudo. O Índice de Qualidade de Aterro de Resíduos (IQAR) é de suma importância, pois criou uma padronização nas avaliações das condições ambientais das instalações, diminuindo o nível de subjetividade e possibilitando o estabelecimento de comparações de maior significância. Depois de preenchido, o formulário nos forneceu o índice IQAR de 5,1 ao Aterro Controlado do Município de Alagoa Grande-PB, enquadrando-se, portanto, em condição inadequada para operação (Tabela $1)$.

É importante frisar que no local não se constatou a presença de catadores, devido a conflitos políticos (permutações de grupos políticos no poder).

\section{Conclusão}

A metodologia desenvolvida nesse trabalho buscou um processo de análise do local de disposição dos resíduos sólidos 
urbanos do município, tomando-se de uma ferramenta decisória. Dentre os macroconjuntos avaliados, utilizando como ferramenta o Índice de Qualidade de Aterro de Resíduos (IQAR) foi detectado que a área onde hoje está instalado o aterro controlado não possui as condições ideais para sua operação, devido a não infraestrutura pra realização das atividades necessárias dentro das normas técnicas e de logística para descarregamento dos resíduos.

A avaliação e identificação dos indicadores presentes no formulário IQAR no aterro estudado, apresentou um baixo índice de qualidade, alcançando a nota 5,1, enquadrando-se em condição inadequada de funcionamento, ou seja, está com a disposição final de resíduos sólidos em total desacordo com a legislação brasileira, de acordo com a Lei ${ }^{\circ} 12.305 / 2010$ e com a NBR 13896/1997. Concluindo, portanto a necessidade urgente de uma manipulação adequada para a disposição final dos resíduos sólidos do município.

\section{Agradecimentos}

Ao Núcleo de Competência em Biocombustíveis e Meio Ambiente (NUBIO); MEC/PROEXT - Ministério da Educação.

\section{Declaração de conflito de interesses}

Os autores declaram não haver conflito de interesses.

\section{Referências}

Adedipe, N. O.; Sridhar, M. K. C.; Baker J. Waste management, processing, and detoxification. In: Chopra, K. (Ed.). Millennium ecosystems assessment. Ecosystems and human wellbeing: Policy responses: findings of the responses working group. Washington, DC: Island Press, 2005. v. 3. p. 313-334.

ABNT - Associação Brasileira de Normas Técnicas. NBR 13896: Aterros de resíduos sólidos não perigosos - critérios para projeto, implantação e operação. Rio de Janeiro: ABNT, 1997.
Brasil. Lei, decretos, etc. Lei $\mathbf{n}^{\mathbf{0}}$ 12.305, de 2 de agosto de 2010. Institui a Política Nacional de Resíduos Sólidos; altera a Lei $\mathrm{n}^{\circ}$ 9.605, de 12 de fevereiro de 1998; e dá outras providências. Disponível em: <http://www.planalto.gov.br/ ccivil_03/_ato2007-2010/2010/lei/112305.htm>. Acesso em: 18 nov. 2015.

Besen, G. R; Günther, W. M. R.; Rodrigues, A. C.; Brasil, A. L. Resíduos sólidos: vulnerabilidades e perspectivas. In: Saldiva, P. Meio ambiente e saúde: o desafio das metrópoles. São Paulo: Ex Libris, 2010. p. 106-123.

Consoni, A. J.; Silva, I. C.; Gimenez, A. F. Disposição final do lixo. In: D'Almeida, M. L. O.; Vilhena, A. (Coords.). Lixo municipal: manual de gerenciamento integrado. 2. ed. São Paulo: Instituto de Pesquisas Tecnológicas - IPT, Compromisso Empresarial para Reciclagem - CEMPRE, 2000. p. 251-291.

IBGE - Instituto Brasileiro de Geografia e Estatística. Alagoa Grande - Infográficos: dados gerais do município. Disponível em: $<$ http://cod.ibge.gov.br/OQK>. Acesso em: 18 nov. 2015.

Ferreira, E. M; Cruvinel, K. A. S, Costa, E. S. C. Disposição final dos resíduos sólidos urbanos: diagnóstico da gestão do Município de Santo Antônio de Goiás. Revista Monografias Ambientais - REMOA, v. 14, n. 3, p. 34013411, 2014.

Instituto Brookfield. Lixão, aterro sanitário e aterro controlado: entenda as diferenças. 2012. Disponível em: <http://blog.institutobrookfield. org.br/index.php/2012/08/entenda-a-diferencaentre-lixao-aterro-controlado-e-aterrosanitario/>. Acesso em: 10 jan.2016.

Jacobi, P. R.; Besen, G. R. Gestão de resíduos sólidos em São Paulo: desafios da sustentabilidade. Estudos Avançados, v. 25, n. 71, p. 135-158, 2011. Disponível em: $<$ http://www.scielo.br/pdf/ea/v25n71/10.pdf $>$. Acesso em: 10 jan.2016.

Reis, F. A. G. V. Módulo 12 - Disposição de Resíduos-5. Formas de Disposição de Resíduos. 2001. Disponível em: $<$ http://www.rc.unesp.br/igce/aplicada/ead/resid uos/res12.html>. Acesso em: 18 nov. 2015. 